JEBв, W. H. H. \& Tomlinson, A. H. (1955). J. gen. Microbiol. 13, 1-8

\title{
The Nutritional Requirements of Haemophilus pertussis
}

\author{
By W. H. H. JEBB and A. H. TOMLINSON \\ Public Health Laboratory, Walton Street, Oxford
}

SUMMARY : Cohen \& Wheeler medium prepared from casein hydrolysate previously treated with charcoal supported the growth of small inocula of Haemophilus pertussis (1-10 organisms $/ \mathrm{ml}$.).

Almost as good growth was obtained from small inocula in medium in which the casein hydrolysate was replaced by a balanced mixture of 17 amino acids and which contained a mixture of growth factors.

Medium containing either cystine and glutamic acid or cystine and aspartic acid as the only amino acids also supported the growth of small inocula; the rate of growth, however, was low.

Nicotinic acid proved to be an essential growth factor for all strains tested. Guanine, hypoxanthine and xanthine enhanced growth although they were not essential. Biotin and haemin, also not essential, enhanced growth during the early phase; this was especially evident with freshly isolated strains.

Hornibrook (1939, 1940) originally showed that phase I Haemophilus pertussis was able to grow in a liquid medium consisting of salts, starch and casein hydrolysate or a mixture of amino acids and that nicotinic acid was necessary for growth. Later workers (Farrell \& Taylor, 1945; Ungar, James, Muggleton, Pegler \& Tomich, 1950; Watanabe, Nishimura \& Tomita, 1952; Imamura, 1952) confirmed the requirement for nicotinic acid. Farrell \& Taylor and Watanabe et al. found thiamine to be essential for some strains, and the latter workers reported stimulation of growth by riboflavin, $p$-aminobenzoic acid and pyridoxine. Imamura (1952) showed that $H$. pertussis would grow in a medium containing cystine and glutamic acid or proline as the only amino acids.

The large inocula (c. $10^{6}$ cells $/ \mathrm{ml}$.) used by all these workers were not satisfactory for nutritional studies, since media which are suitable for the growth of large inocula are frequently inadequate for small inocula. This present study was undertaken to determine the requirements for full growth of small inocula.

\section{MATERIALS AND METHODS}

Strains. The strains used were isolated in this laboratory; some were kept freeze-dried until required and others tested within 12 days after isolation. Strain 724, was used in a previous study (Jebb \& Tomlinson, 1951). Strains in constant use were re-dried by Stamp's (1947) method and a fresh tube opened monthly. Periodic tests showed that the strains always agglutinated to titre with phase I serum.

Preparation of inocula. A 1- or 2-day old culture on Bordet-Gengou medium was inoculated heavily on to the same medium and incubated at $35^{\circ}$ for $18 \mathrm{hr}$. 
The growth was washed off with saline, centrifuged, washed twice with saline, resuspended to a known opacity and diluted for use. Counts performed occasionally showed that the usual inoculum contained $c .10^{3}$ viable cells.

Conditions of incubation and measurement of growth. In order to keep the surface to volume ratio as high as possible and to enable the optical density to be read directly in the growth vessels, $5 \mathrm{ml}$. of medium were placed in $6 \times 5 \frac{5}{8}$ in. test tubes bent, at an angle of $45^{\circ}, 1 \frac{1}{2}$ in. from the open end. The tubes were fitted with aluminium caps and incubated horizontally at $35^{\circ}$. In these tubes growth after $90 \mathrm{hr}$. was 6 times as great as that in vertical test tubes.

Growth was measured turbidimetrically against uninoculated blanks, using a Hilger 'Biochem' absorptiometer with a blue filter (Chance OB 2). The figures given are the means of the extinctions for triplicate tubes. The extinction was proportional to the number of cells up to a reading of 0.85 , and a reading of 0.50 was equivalent to $270 \mu \mathrm{g}$. dry wt. $/ \mathrm{ml}$. or $c .1 \cdot 3 \times 10^{10} \mathrm{cells} / \mathrm{ml}$. (American standard for pertussis vaccine).

Modified Cohen \& Wheeler medium (C.W.). Cohen \& Wheeler medium (1946) was chosen as the control. This medium prepared according to their method was unable to support the growth of inocula smaller than $10^{6} \mathrm{cells} / \mathrm{ml}$. When, however, the casein hydrolysate (Difco Casamino Acids, Technical) was adsorbed with charcoal, for the purpose of removing growth factors, it was found that the resulting medium supported the growth of small inocula of the order of 1-10 organisms/ml. - the charcoal, presumably, had removed some growth inhibitor. The following further modifications also gave better and more consistent growth: (i) calcium and copper salts were omitted and the amount of magnesium chloride reduced to one-tenth; (ii) cysteine was replaced by cystine; (iii) the $\mathrm{pH}$ was raised to $7 \cdot 9$ (cf. Ungar et al. 1950); and (iv) the yeast dialysate was decreased to $1 \cdot 25 \%$.

The method finally adopted for preparing the modified C.W. medium was as follows: $20 \mathrm{~g}$. Casamino Acids were dissolved in a litre of distilled water, adjusted to $\mathrm{pH} 2 \cdot 4$ and adsorbed with $6 \mathrm{~g}$. of Norit charcoal (Harrington) at $100^{\circ}$ for $30 \mathrm{~min}$. The mixture was filtered and adjusted to $\mathrm{pH} 6 \cdot 8$ and adsorbed again with charcoal at $100^{\circ}$ for $30 \mathrm{~min}$. The mixture was filtered, and $6 \mathrm{~g}$. charcoal were added and the whole allowed to stand at room temperature for $2 \mathrm{hr}$. After filtering the volume was made up to $1 \mathrm{l}$. The solution was stored frozen and made into medium as required: adsorbed casein hydrolysate solution, $500 \mathrm{ml}$; $\mathrm{KH}_{2} \mathrm{PO}_{4}, 0.5 \mathrm{~g}$.; $\mathrm{NaCl}, 2.5 \mathrm{~g}$; $\mathrm{MgCl}_{2} .6 \mathrm{H}_{2} \mathrm{O}, 0.04$ g.; $\mathrm{FeSO}_{4} .7 \mathrm{H}_{2} \mathrm{O}, 0.01 \mathrm{~g}$; L-cystine, $25 \mathrm{mg}$; soluble starch, $1.5 \mathrm{~g}$.; water to $800 \mathrm{ml}$. The casein hydrolysate, water and starch were boiled for $7 \mathrm{~min}$. After cooling, the salts and cystine were added, the volume made up to $800 \mathrm{ml}$. and the $\mathrm{pH}$ adjusted to $\mathbf{7 \cdot 9}$. The mixture was brought to the boil and filtered. The medium was distributed in $4 \mathrm{ml}$. lots and autoclaved at $15 \mathrm{lb}$. sq. in for $10 \mathrm{~min}$. Before inoculation $0.5 \mathrm{ml}$. of water and $0.5 \mathrm{ml}$. of yeast dialysate (Cohen \& Wheeler, 1946), diluted $1 / 8$, were added.

Basal medium for testing growth factor requirements $(B 1)$. This was the same as the modified C.W. medium without the yeast dialysate. In some experiments the soluble starch was omitted and a Seitz-filtered solution of crystalline 
bovine albumin (Armour), to give a final concentration of $0 \cdot 1 \%(w / v)$, was added after the rest of the basal medium had been autoclaved.

Basal medium for testing amino acid requirements $(\boldsymbol{B 2})$. This was prepared in the same way as the modified C.W. medium but $3 \cdot 7 \mathrm{~g}$. $\mathrm{NaCl} / \mathrm{l}$. was added in place of the casein hydrolysate, and the following growth factors in place of the yeast dialysate: $10^{-5} \mathrm{M}$-nicotinic acid, $6 \mu \mathrm{g}$. guanine $/ \mathrm{ml} ., 6 \mu \mathrm{g}$. hypoxanthine $/ \mathrm{ml}$., $6 \mu \mathrm{g}$. xanthine $/ \mathrm{ml}$, $1 \cdot 0 \mu \mathrm{g}$. haemin $/ \mathrm{ml}$., $50 \mathrm{~m} \mu \mathrm{g}$. biotin $/ \mathrm{ml}$. (final concentrations).

Growth factors and amino acids. These were commercial preparations obtained from British Drug Houses Ltd., Roche Products Ltd., and L. Light and Co. Ltd. Solutions were sterilized by autoclaving at $15 \mathrm{lb}$. pressure for $10 \mathrm{~min}$.

\section{EXPERIMENTAL}

\section{Growth factor requirements}

Tests were made with the following 19 growth factors, using the concentrations shown in Table 1: biotin, calcium pantothenate, riboflavin, thiamine hydrochloride, $p$-aminobenzoic acid, haemin, pyridoxine, folic acid, choline chloride, spermine phosphate, guanine, adenine, xanthine, hypoxanthine, cytosine, uracil, thymine, inositol and nicotinic acid. Various mixtures of growth factors were prepared and $0.5 \mathrm{ml}$. of each mixture was added to $4 \mathrm{ml}$. of basal medium B1 containing either starch or albumin, and the volume made up to $5 \mathrm{ml}$. Each tube was inoculated with approximately $10^{3}$ organisms, and the growth recorded each day. Modified C.W. medium was also inoculated and used as a control.

Table 1. Tests for growth factor requirements of Haemophilus pertussis

Each tube contained basal medium B1 and growth factors to a total volume of $5 \mathrm{ml}$. Concentrations of growth factors $\left(\mu \mathrm{g} . / \mathrm{ml}\right.$. medium): $5 \times 10^{-3}$ biotin, 1.0 calcium pantothenate, $0 \cdot 25$ riboflavin, $0 \cdot 25$ thiamine hydrochloride, $0 \cdot 1 p$-aminobenzoic acid, $1 \cdot 0$ haemin, $1 \cdot 0$ pyridoxine, $0 \cdot 1$ folic acid, $2 \cdot 0$ choline chloride, $1 \cdot 0$ spermine phosphate, $5 \cdot 0$ guanine, $5 \cdot 0$ adenine, $5 \cdot 0$ xanthine, 5.0 hypoxanthine, 5.0 cytosine, 5.0 uracil, 5.0 thymine, 5.0 inositol. Nicotinic acid $10^{-5} \mathrm{M}$. Inoculum: $10^{3}$ cells. Growth as extinction after 4 days.

Growth factor omitted

All
None
Purines
Nicotinic acid
Any of the other factors
Control (yeast extract)

\begin{tabular}{|c|c|c|c|}
\hline \multicolumn{2}{|c|}{ Strain $\mathbf{7 2 4}$} & \multicolumn{2}{|c|}{ Strain 3256} \\
\hline Starch & Albumin & Starch & Albumin \\
\hline \multicolumn{4}{|c|}{ Growth } \\
\hline 0.01 & 0.02 & 0.00 & $0 \cdot 02$ \\
\hline 0.76 & $0 \cdot 69$ & $0 \cdot 70$ & 0.73 \\
\hline 0.27 & 0.42 & $0 \cdot 39$ & $0 \cdot 46$ \\
\hline 0.02 & 0.03 & 0.01 & 0.00 \\
\hline $0.85-0.51$ & $0.68-0.51$ & $0.78-0.56$ & $0.78-0.57$ \\
\hline 0.76 & 0.54 & 0.55 & 0.54 \\
\hline
\end{tabular}

The results ('Table 1) show that a mixture of the 19 growth factors gave as good or better growth than yeast dialysate, that the omission of nicotinic acid completely prevented growth, and that the omission of the purines decreased 
but did not prevent growth. Omission of other factors produced slight variations in growth, but no one appeared to be significant.

Nicotinic acid. Titration of nicotinic acid and nicotinamide, with the other factors present at the concentrations in Table 1, showed that full growth was obtained with $4 \times 10^{-7} \mathrm{M}$ of either.

Purines. When added to the basal medium B1 with all the other factors given in Table 1, guanine, hypoxanthine or xanthine at $5 \mu \mathrm{g} . / \mathrm{ml}$. all produced equal stimulation of growth. Adenine alone produced neither stimulation nor inhibition, but added together with the other purines it decreased their stimulating effect. To determine the optimum level of purines a mixture was prepared containing equal quantities of guanine, xanthine and hypoxanthine, and dilutions of this were added to the basal medium $\mathrm{B} 1$ containing nicotinic acid. A total purine content of $18 \mu \mathrm{g} . / \mathrm{ml}$. gave a growth at $93 \mathrm{hr}$. which was twice as dense as that without the purines, but higher levels produced only a further slight increase.

Biotin and haemin. The basal medium B1, with starch, was supplemented with the optimal levels of nicotinic acid, guanine, xanthine and hypoxanthine and to this were added mixtures of the other growth factors from which each was omitted in turn. Under these conditions the omission of biotin and haemin consistently reduced growth in the early stages, whereas the omission of the other factors was without effect. This early stimulation by biotin and haemin was most evident with freshly isolated strains (Table 2).

\section{Table 2. Effect of biotin and haemin on the growth of freshly isolated strains}

Each tube contained basal medium B1 and growth factors to a total volume of $5 \mathrm{ml}$. Concentration of growth factors. Nicotinic acid $10^{-5} \mathrm{M}$. Purines: guanine, xanthine and hypoxanthine each at $6 \mu \mathrm{g} . / \mathrm{ml}$. Biotin $50 \mathrm{~m} \mu \mathrm{g} . / \mathrm{ml}$. Haemin $1.0 \mu \mathrm{g} . / \mathrm{ml}$. Inoculum $10^{3}$ cells. Growth as extinction after 4 days. Experiment performed within 11 days of taking swab from patient.

\begin{tabular}{|c|c|c|c|c|c|c|}
\hline \multirow[b]{2}{*}{ Strain } & \multicolumn{6}{|c|}{ Growth } \\
\hline & $\begin{array}{c}\text { Basal } \\
\text { medium B1 }\end{array}$ & $\begin{array}{c}\text { B } 1+\text { yeast } \\
\text { extract }\end{array}$ & $\begin{array}{l}\text { B1 + growth } \\
\text { factors }\end{array}$ & $\begin{array}{l}\mathrm{B} 1+\text { nico- } \\
\text { tinic acid }\end{array}$ & $\begin{array}{l}\text { B } 1+\text { nico- } \\
\text { tinic acid } \\
\text { and purines }\end{array}$ & $\begin{array}{c}\text { B } 1+\text { nicotinic } \\
\text { acid, purines, } \\
\text { biotin and } \\
\text { haemin }\end{array}$ \\
\hline 6294 & 0.00 & $0 \cdot 32$ & 0.44 & 0.21 & $0 \cdot 37$ & $0 \cdot 66$ \\
\hline 3886 & 0.00 & 0.53 & 0.72 & $0 \cdot 33$ & 0.58 & 0.77 \\
\hline
\end{tabular}

Other strains. The findings in Table 1 were confirmed with four other dried strains and five strains tested within 11 days of taking the swab from the patient.

\section{Amino acid requirements}

Tests were made with the following 17 amino acids, using the concentrations shown in Table 3: L-alanine, L-arginine, L-aspartic acid, L-cystine, L-glutamic acid, glycine, L-histidine, L-isoleucine, L-leucine, L-lysine, L-methionine, L-phenylalanine, L-proline, DL-serine, DL-threonine, L-tyrosine, and L-valine. 
Media were prepared by adding various mixtures of amino acids to the basal medium B2. Tubes of media were inoculated with $c .10^{3}$ cells and the growth recorded each day. A medium containing casein hydrolysate in place of the amino acids was used as a control.

The results recorded in Table 3 show that the medium containing all 17 amino acids supported growth but not as well as the control medium; the omission of glycine prevented growth; the omission of glutamic acid or cystine restricted growth markedly, and the effect of omitting leucine or isoleucine was different with different strains.

\section{Table 3. Tests for amino acid requirements of Haemophilus pertussis}

Each tube contained basal medium B2 and amino acids to a total volume of $5 \mathrm{ml}$. Concentration of amino acids $\left(\times 10^{-4} \mathrm{M}\right): 2.7 \mathrm{~L}$-alanine, $8.0 \mathrm{~L}$-arginine, $6.0 \mathrm{~L}$-aspartic acid, 1.0 L-cystine, 100.0 L-glutamic acid, 3.0 glycine, $1.7 \mathrm{~L}$-histidine, $4 \cdot 0 \mathrm{~L}$-isoleucine, $6 \cdot 0 \mathrm{~L}$-leucine, 5.0 L-lysine, $4.0 \mathrm{~L}$-methionine, $0.5 \mathrm{~L}$-phenylalanine, $7.3 \mathrm{~L}$-proline, $2.0 \mathrm{DL}$-serine, $2.0 \mathrm{DL}$-threonine, 4.0 L-tyrosine, $1.5 \mathrm{~L}$-valine. Inoculum: $10^{3}$ cells. Growth as extinction after 5 days.

\begin{tabular}{|c|c|c|c|}
\hline \multirow{3}{*}{ Amino acid omitted } & \multicolumn{3}{|c|}{ Strain } \\
\hline & 724 & 446 & 17790 \\
\hline & \multicolumn{3}{|c|}{ Growth } \\
\hline None & $0 \cdot 68$ & $0 \cdot 79$ & $0 \cdot 76$ \\
\hline Glutamic acid & $0 \cdot 13$ & $0 \cdot 11$ & $0 \cdot 10$ \\
\hline Glycine & 0.02 & 0.08 & 0.05 \\
\hline Leucine & 0.59 & 0.71 & $0 \cdot 35$ \\
\hline Isoleucine & $0 \cdot 24$ & $0 \cdot 66$ & 0.54 \\
\hline Cystine & $0 \cdot 17$ & $0 \cdot 16$ & $0 \cdot 15$ \\
\hline Any of the other acids & $0 \cdot 79-0 \cdot 61$ & $0 \cdot 88-0.72$ & $0.84-0.72$ \\
\hline $\begin{array}{l}\text { Control (stock casein } \\
\text { hydrolysate) }\end{array}$ & 0.96 & 0.97 & 0.95 \\
\hline
\end{tabular}

A medium was also prepared containing a mixture of amino acids of approximately the same composition as casein hydrolysate (based on the data of Block \& Bolling, 1951). This, however, did not support the growth of small inocula, nor did a medium containing the mixtures of amino acids used by Hornibrook (1940) or Pollock (1949).

Freshly isolated strains. Six strains tested within 13 days of taking the swab from the patient grew in media containing amino acid mixtures at the same rate as the dried strains.

Replacement of glutamic acid. It is evident from Table 3 that glutamic acid was not essential for the growth of Haemophilus pertussis. Since, however, glutamic acid was the amino acid present in the highest concentration and since it was previously shown (Jebb \& Tomlinson, 1951) that it was most rapidly oxidized by resting suspensions, it is probably the principal energy source for growth in these media. It was also shown previously that aspartic acid, proline, alanine, succinate and lactate were oxidized by resting suspensions. To determine whether these substances could replace glutamic acid, a basal medium was prepared containing all the amino acids in Table 3 except glutamic acid and to tubes of this were added glutamic acid, proline, aspartic 
acid and alanine at $0.01 \mathrm{~m}$ final concentration and succinate and lactate at $0.02 \mathrm{M}$. Glucose, which was not oxidized, was also added to a tube of the basal medium at $0.01 \mathrm{M}$. Tubes were inoculated with $c .10^{3}$ cells. The growth with aspartic acid, alanine, proline and lactate was $30-60 \%$ of that with glutamic acid, whereas growth with glucose and succinate was no greater than that in the basal medium.

Growth in simplified media. To determine whether a single amino acid could act as a sole source of energy, carbon and nitrogen, media were prepared with salts, starch, cystine and growth factors as in previous amino acid experiments, and either glutamic or aspartic acids or proline or alanine at $0.01 \mathrm{~m}$ final concentration. Tubes were inoculated with $c .10^{6}$ and $c .10^{3}$ cells. The medium containing alanine did not support growth, only large inocula grew in the medium containing proline, whereas small inocula grew slowly in media containing glutamic acid or aspartic acid.

Antagonism between amino acids. As the organism grew in a medium containing only cystine, glutamic or aspartic acid, salts and starch, it was apparent that glycine, isoleucine and leucine were not essential for growth. The reduction of growth on omitting these acids from mixtures (Table 3) was presumably due to inhibition by other amino acids. Preliminary investigations showed that two series of amino acids were involved: (1) isoleucine, leucine and valine, and (2) glycine, methionine, proline and serine. Two experiments were performed omitting the appropriate amino acids singly and in combination (Table 4). The results of Expt. 1 showed that valine was inhibitory and that the inhibition was counteracted by isoleucine or leucine, but most strongly by both together. From the results of Expt. 2 it appeared that glycine overcame an inhibition caused by methionine, proline and serine in combination. Slight inhibition was produced in the absence of glycine by these acids singly or in pairs, but the full effect was only observed when all three acids were present together.

\section{Table 4. Antagonisms between amino acids}

Each tube contained basal medium $\mathrm{B} 2$ and amino acids to a total volume of $5 \mathrm{ml}$. Concentrations of amino acids $\left(\times 10^{-4} \mathrm{M}\right): 2.7 \mathrm{~L}$-alanine, $8.0 \mathrm{~L}$-arginine, $6.0 \mathrm{~L}$-aspartic acid, 1.0 L-cystine, 100.0L-glutamic acid, 3.0 glycine, $1.7 \mathrm{~L}$-histidine, $4.0 \mathrm{~L}$-isoleucine, $6.0 \mathrm{~L}$ leucine, 5.0 L-lysine, $4.0 \mathrm{~L}$-methionine, $0.5 \mathrm{~L}$-phenylalanine, $7.3 \mathrm{~L}$-proline, $2.0 \mathrm{DL}$-serine, 2.0 DL-threonine, $4.0 \mathrm{~L}$-tyrosine, $1.5 \mathrm{~L}$-valine. Inoculum: $10^{3}$ cells. Growth as extinction after 5 days.

Experiment 1

$\begin{array}{lc}\text { Acid omitted } & \text { Growth } \\ \text { None } & 0 \cdot 45 \\ \text { Isoleucine } & 0 \cdot 31 \\ \text { Leucine } & 0 \cdot 30 \\ \text { Valine } & 0 \cdot 53 \\ \text { Isoleucine and leucine } & 0 \cdot 13 \\ \text { Isoleucine, leucine and } & 0 \cdot 26 \\ \text { valine } & \end{array}$

Experiment 2

\begin{tabular}{lc}
\hline Acid omitted & Growth \\
None & 0.35 \\
Glycine & $0 \cdot 03$ \\
Methionine, proline and serine & 0.25 \\
Glycine, methionine, proline & 0.21 \\
and serine &
\end{tabular}

Racemic amino acids. During experiments to devise the medium described in Table 3, it appeared that growth was slower in media containing racemic 
amino acids than in those containing the L-acids. An experiment in which three strains were inoculated into media prepared with racemic and L-acids showed that growth was consistently better in media prepared with the L-acids.

\section{DISCUSSION}

This study differs from most of the previous work on the growth requirements of Haemophilus pertussis in that small washed inocula (c. 200 cells/ml.) were used throughout as compared with $4 \times 10^{6} / \mathrm{ml}$. used by Ungar et al. (1950); 3 billion $/ 5 \mathrm{ml}$. by Watanabe et al. (1952); $2 \times 10^{7} / \mathrm{ml}$. used by Farrell \& Taylor (1945); and 1 loopful of suspension (1 mg./ml.) in $2 \mathrm{ml}$. used by Imamura (1952).

The only vitamin absolutely required by the 16 strains used in this work was nicotinic acid (or nicotinamide) and none of them had a requirement for thiamine or a complex supplement as found by Farrell \& Taylor (1945). Growth was stimulated by guanine, xanthine and hypoxanthine but not by adenine, riboflavin, $p$-aminobenzoic acid or pyridoxine, in contrast to the findings of Watanabe et al. (1952). The early growth of freshly isolated strains was stimulated by biotin and haemin, but this effect was only slight with the dried strains.

No one amino acid appeared to be essential for the growth of Haemophilus pertussis. In contrast with the findings of Ungar et al. (1950) omission of cystine limited but did not prevent growth, so that the organism could apparently use methionine or sulphate as source of sulphur. Imamura (1952) reported good growth with hyposulphite or thioglycollate and slight growth with methionine, taurine or sodium sulphite, but no growth with sulphate. In a casein hydrolysate medium, the glutamate appeared to serve as the source of energy, and in a mixture of amino acids glutamate could be replaced by alanine, proline, aspartic acid or lactate.

As in the case of other organisms (Gladstone, 1939; Washburn \& Niven, 1948; Rowley, 1953) the balance of amino acids was important. Valine in the absence of isoleucine and leucine was inhibitory, and so were methionine, proline and serine, in combination, in the absence of glycine. Dawson, Farnworth, McLeod \& Nicholson (1951) reported inhibition of Haemophilus pertussis by high concentrations of serine.

It is thus evident that Haemophilus pertussis does not have elaborate nutritional requirements. The difficulties frequently encountered in growing this organism are probably due to inhibitors in the medium (Pollock, 1947, 1949; Fisher, 1948).

We are indebted to Mr H. A. Tarr for technical assistance.

\section{REFERENCES}

Block, R. J. \& Boluing, D. (1951). The Amino Acid Composition of Proteins and Foods. Springfield, U.S.A.: C. C. Thomas.

Cohen, S. M. \& Wheeler, M. W. (1946). Pertussis vaccine prepared with phase I cultures grown in fluid medium. Amer. J. publ. Hlth, 36, 371. 
Dawson, B., Farnworth, E. H., McLeod, J. W. \& Nicholson, D. E. (1951). Observations on the value of the Bordet-Gengou medium for the cultivation of Haemophilus pertussis. J. gen. Microbiol. 5, 408.

Farrell, L. \& Taylor, E. M. (1945). Notes on the production of phase I pertussis vaccine in fluid medium. Canad. publ. Htth J. 36, 326.

Fisher, S. (1948). The behaviour of Haemophilus pertussis in casein hydrolysate broth. Austr. J. exp. Biol. 26, 299.

Gladstone, G. P. (1939). Inter-relationships between amino acids in nutrition of B. anthracis. Brit. J. exp. Path. 20, 189.

Hornibrook, J. W. (1939). Cultivation of phase I $H$. pertussis in a semi-synthetic liquid medium. Publ. Hlth Rep. Wash. 54, 1847.

Hornibrook, J. W. (1940). Nicotinic acid as a growth factor for $\mathrm{H}$. pertussis. Proc. Soc. exp. Biol., N.Y. 45, 598.

ImamurA, P. S. (1952). Growth requirements of Haemophilus pertussis with special reference to the production of thermolabile toxin. Japan. J. exp. Med. 22, 49.

Jевв, W. H. H. \& Tomlinson, A. H. (1951). The catabolic activity of washed suspensions of Haemophilus pertussis. J. gen. Microbiol. 5, 951.

Pollock, M. R. (1947). The growth of $H$. pertussis on media without blood. Brit. J. exp. Path. 28, 295.

Pollock, M. R. (1949). The effects of long-chain fatty acids on the growth of Haemophilus pertussis and other organisms. Symp. Soc. exp. Biol. 3, 193.

Rowley, D. (1953). Inhibition of E. coli strains by amino acids. Nature, Lond. 171, 80.

STAMP, LoRD (1947). The preservation of bacteria by drying. J. gen. Microbiol. 1, 251.

Ungar, J., James, A. M., Muggleton, P. W., Pegler, H. F. \& 'омmch, E. G. (1950). The cultivation of Haemophilus pertussis in partially defined liquid media. J. gen. Microbiol. 4, 345.

Washburn, M. R. \& Nrven, Jun. C. F. (1948). Amino acid interrelationships in the nutrition of Streptococcus bovis. J. Bact. 55, 769.

Watanabe, Y., Nishimura, T. \& Tomita, S. (1952). On a semisynthetic fluid medium for the growth of Haemophilus pertussis. Kitasato Arch. 25, 1. 